\title{
Subtidal Salinity and Velocity in the Hudson River Estuary: Observations and Modeling
}

\author{
David K. Ralston, W. Rockwell Geyer, and James A. LerczaK* \\ Woods Hole Oceanographic Institution, Woods Hole, Massachusetts
}

(Manuscript received 20 March 2007, in final form 31 August 2007)

\begin{abstract}
A tidally and cross-sectionally averaged model based on the temporal evolution of the quasi-steady Hansen and Rattray equations is applied to simulate the salinity distribution and vertical exchange flow along the Hudson River estuary. The model achieves high skill at hindcasting salinity and residual velocity variation during a 110-day period in 2004 covering a wide range of river discharges and tidal forcing. The approach is based on an existing model framework that has been modified to improve model skill relative to observations. The external forcing has been modified to capture meteorological time-scale variability in salinity, stratification, and residual velocity due to sea level fluctuations at the open boundary and alongestuary wind stress. To reflect changes in vertical mixing due to stratification, the vertical mixing coefficients have been modified to use the bottom boundary layer height rather than the water depth as an effective mixing length scale. The boundary layer parameterization depends on the tidal amplitude and the local baroclinic pressure gradient through the longitudinal Richardson number, and improves the model response to spring-neap variability in tidal amplitude during periods of high river discharge. Finally, steady-state model solutions are evaluated for both the Hudson River and northern San Francisco Bay over a range of forcing conditions. Agreement between the model and scaling of equilibrium salinity intrusions lends confidence that the approach is transferable to other estuaries, despite significant differences in bathymetry. Discrepancies between the model results and observations at high river discharge are indicative of limits at which the formulation begins to fail, and where an alternative approach that captures two-layer dynamics would be more appropriate.
\end{abstract}

\section{Introduction}

Understanding the structure and variability of the salinity distribution in an estuary is critical to many ecological and engineering management decisions. The salinity distribution is governed by a balance between downstream advection of salt by river flow and upstream transport of salt by dispersive processes. These up-estuary fluxes can be divided into a subtidal component due to residual velocity and salinity and an oscillatory tidal component associated with correlations in velocity and salinity at tidal time scales (Hansen and Rattray 1965; Fischer et al. 1979). For the subtidal salt

\footnotetext{
* Current affiliation: College of Oceanic and Atmospheric Sciences, Oregon State University, Corvallis, Oregon.
}

Corresponding author address: David K. Ralston, Applied Ocean Physics and Engineering, MS \#12, Woods Hole Oceanographic Institution, Woods Hole, MA 02543.

E-mail: dralston@whoi.edu flux, the baroclinic pressure gradient creates vertical structure in residual velocity and salinity, as saltier water moves upstream near the bed and fresher water moves downstream near the surface (Taylor 1953; Chatwin 1976). While this vertical residual dominates the upstream transport of salt in many estuaries, lateral residual structure due to bathymetry can also contribute to the longitudinal salt flux (Fischer 1972). Oscillatory tidal dispersion depends on local bathymetry and forcing and can incorporate processes such as tidal pumping, lateral trapping, and oscillatory tidal shear dispersion (Stommel and Farmer 1952; Okubo 1973; Dronkers and van de Kreeke 1986; Fischer et al. 1979).

The instantaneous structure of the salinity distribution in an estuary depends on the response to unsteady forcing from river discharge and tides over time scales ranging from days (river discharge after precipitation events) to weeks (spring-neap variability in tidal amplitude) to months (seasonal discharge variability). Analytical theories with simplifying assumptions have been developed to predict equilibrium salinity distribu- 
tions for steady forcing (Hansen and Rattray 1965; Fischer 1972; Chatwin 1976). The equilibrium solutions have been used to explain empirical correlations between river discharge $\left(Q_{r}\right)$ and estuarine salinity intrusion length $\left(L_{x}\right)$, typically of the form $L_{x}=Q_{r}^{n}$ (Abood 1974; Monismith et al. 2002). Recently, investigators have recognized that unsteadiness is often critical to the salt balance and that the estuarine adjustment to changes in forcing can be too slow for the estuary to reach equilibrium before the forcing changes (Kranenberg 1986; MacCready 1999; Hetland and Geyer 2004; Banas et al. 2004; MacCready 2007; Lerczak et al. 2007, manuscript submitted to J. Phys. Oceanogr., hereafter LGR).

In addition to baroclinic forcing, both local and remote winds can significantly impact the residual velocity and the net transport. Local winds along the estuary axis force two-layer flow with the wind at the surface and against the wind at the bed (Hansen and Rattray 1965). Here we only consider the vertical structure of the residual velocity and ignore any lateral variability induced by local winds (e.g., Csanady 1973). Remote winds generate coastal Ekman setup or setdown that pumps water into or out of the estuary at the open boundary. Remote winds generally have greater effects than local winds on the barotropic exchange at the mouth and on water level in the estuary (Wang and Elliott 1978; Wang 1979; Garvine 1985; Wong and Moses-Hall 1998; Wong and Valle-Levinson 2002). However, the vertical exchange flow driven by local winds can alter the residual velocity and stratification and at times can create salt flux comparable to or greater than that due to baroclinic forcing (Weisberg 1976; Wang 1979; van de Kreeke and Robaczewska 1989; Noble et al. 1996; Geyer 1997; Janzen and Wong 2002; Wong and Valle-Levinson 2002). Wind effects are typically in the meteorological frequency band, with periods of 2 to 5 days, and can be highly seasonal depending on prevailing wind orientation, frequency of wind events, and background stratification.

Salt flux mechanisms vary in relative importance in different estuaries. This study focuses on the Hudson River estuary, where empirical scaling of the salinity intrusion with respect to $Q_{r}$ indicates that for low to moderate river discharge $L_{x} \sim Q_{r}^{-0.38}$, while for high discharge $\left(Q_{r}>800 \mathrm{~m}^{3} \mathrm{~s}^{-1}\right) L_{x} \sim Q_{r}^{-1.19}$ (Abood 1974; Wells and Young 1992). Studies in the Hudson have consistently found that residual shear dominates the up-estuary salt flux (Hunkins 1981; Bowen and Geyer 2003; Lerczak et al. 2006). Effective dispersion rates due to residual shear are roughly 10 times greater than for tidal processes and, because of the relatively uniform channel geometry, the salt flux due to the vertical baroclinic shear is substantially greater than that due to the lateral shear (Lerczak et al. 2006). Dispersive fluxes in the Hudson are temporally variable, up to an order of magnitude greater during neap tides than during springs (Bowen and Geyer 2003; Lerczak et al. 2006). The spring-neap fluctuations in salt flux create a highly unsteady salt balance with salt moving out of the estuary during spring tides and up-estuary during neaps. Over several days, increases in river discharge advect the salinity intrusion downstream, and fluctuations in tidal forcing and discharge can change the total salt in the estuary by a factor of 4 or more (Lerczak et al. 2006). Over meteorological time scales, local or remote winds can significantly alter the salt flux, even switching the direction of the advective component toward up-estuary for brief periods (Bowen and Geyer 2003; Lerczak et al. 2006).

In this work, we evaluate how well a simple model of the tidally averaged salt flux can represent the structure and variability of the salinity distribution and the residual shear in the Hudson River estuary. Three-dimensional hydrodynamic models have been applied to simulate the salinity field in the Hudson (Warner et al. 2005) and in other estuaries such as Chesapeake Bay (Li et al. 2005). While these models can simulate estuarine conditions with great detail, simpler models offer some benefits. Because of their reduced complexity, simple models more readily permit isolation and identification of basic mechanisms and can be run economically for longer simulations or more varied scenarios. To calculate the time-dependent estuarine salinity distribution, we locally apply the quasi-steady Hansen and Rattray solution for residual shear and stratification to determine the subtidal up-estuary salt flux. We parameterize the vertical mixing and oscillatory tidal dispersion and numerically solve the resulting along-estuary advection-diffusion equation for the time-varying salinity distribution (MacCready 2007). We compare the model results with observations of currents and salinity at a series of locations in the Hudson over several months, covering a range of tidal amplitude and river discharge conditions.

Based on the discrepancies between the model results and observations, we hypothesize missing processes that might be important for simulating the subtidal salinity field and then implement appropriate modifications to the model. We modify the external forcing, adding barotropic flux at the downstream boundary due to remote winds and residual velocity due to local winds, and modify the mixing parameterization, limiting the mixing length scale due to stratification. We test the contribution of each of these modifications to the model's ability to represent observed 
subtidal salinity and velocity distributions. Finally, we study the time-independent limit of this quasi-steady model to assess equilibrium salinity distributions, both with and without the modifications to mixing parameterization. We compare the equilibrium results with observations and with empirical scaling of the equilibrium salinity intrusions in the Hudson and in San Francisco Bay.

\section{Model development}

The model presented here is a tidally averaged, width-averaged solution for the salinity distribution in an estuary. The model builds off a time-dependent application (MacCready 2004, 2007) of the quasi-steady Hansen and Rattray (1965) solution for estuarine circulation and residual stratification. The model solves a one-dimensional (along estuary), time-dependent advection/diffusion equation for the depth-averaged salinity field using analytic expressions to represent the vertical variability of velocity and salinity. In this work we have taken the basic model framework from MacCready (2007), but have modified the external forcing and the vertical mixing parameterizations. Based on field observations, we noted that meteorological band fluctuations in forcing significantly impacted residual velocities and the salinity distribution. To incorporate this, we altered the river velocity in the model to include short-term but relatively large magnitude variability associated with sea level fluctuations at the downstream boundary. We have also modified the residual velocity and salinity profiles to include effects of along-estuary wind according to the Hansen and Rattray solution. Finally, we have modified the parameterization of the tidally averaged vertical mixing coefficients for momentum and salinity. We have simplified the functional form of the parameterization by reducing the number of adjustable coefficients and have incorporated effects of stratification on vertical mixing through changes in the mixing length scale. During periods with high river discharge and weak tidal mixing, strong stratification reduces the scale for turbulent overturns from the full water depth to the height of the bottom boundary layer, which is quantified with a horizontal Richardson number formulation.

The model variables are along-channel velocity $u(x, z, t)$ and salinity $s(x, z, t)$, and each is divided into depth-averaged (overbar) and deviations from depthaveraged (prime) components so that $u=\bar{u}(x, t)+$ $u^{\prime}(x, z, t)$ and $s=\bar{s}(x, t)+s^{\prime}(x, z, t)$. The depthaveraged velocity $\bar{u}$ is imposed, but the other three components are dependent variables. In MacCready (2007), $\bar{u} \equiv Q_{r} / A$, where $Q_{r}$ is the river discharge and $A$ is the cross-sectional area. We have modified the defi- nition of $\bar{u}$ to incorporate meteorological band variability resulting from subtidal fluctuations in water elevation at the open boundary.

The vertical profiles of velocity shear and stratification use the Hansen and Rattray (1965) polynomial functions based on the local depth-averaged longitudinal salinity gradient $(\partial \bar{S} / \partial x)$, and the depth-averaged velocity $(\bar{u})$. Details on the derivation of the $u^{\prime}$ and $s^{\prime}$ profiles can be found in MacCready (2004). We have modified $u^{\prime}$ and $s^{\prime}$ to include effects of along-estuary wind (Hansen and Rattray 1965; Geyer 1997). The tidally averaged shear depends on $\bar{u}$, the estuarine exchange velocity $\left(u_{e}\right)$, and the wind-induced exchange velocity $\left(u_{w}\right)$ :

$$
\begin{aligned}
u^{\prime} & =\bar{u} P_{u 1}+u_{e} P_{u 2}+u_{w} P_{u 3}, \\
P_{u 1} & =\frac{1}{2}-\frac{3}{2} \zeta^{2}, \quad P_{u 2}=1-9 \zeta^{2}-8 \zeta^{3}, \\
P_{u 3} & =1+4 \zeta+3 \zeta^{2},
\end{aligned}
$$

where $\zeta \equiv z / H$ is the normalized depth (between 0 and $-1), u_{e}=g \beta(\partial \bar{S} / \partial x) H^{3} /\left(48 K_{m}\right), K_{m}$ is an effective eddy viscosity, $u_{w}=\tau_{w} H /\left(4 \rho K_{m}\right)$, and $\tau_{w}$ is the along-estuary wind stress. The thalweg depth is $H$, and the density anomaly is assumed to depend on salinity according to $\rho=\rho_{0}(1+\beta \bar{s})$, where $\beta=7.7 \times 10^{-4} \mathrm{psu}^{-1}$. Similarly, the deviations from depth-averaged salinity depend on $\bar{u}, u_{e}$, and $u_{w}$ :

$$
\begin{aligned}
s^{\prime} & =\frac{H^{2}}{K_{S}}(\partial \bar{s} / \partial x)\left(\bar{u} P_{s 1}+u_{e} P_{s 2}+u_{w} P_{s 3}\right), \\
P_{s 1} & =-\frac{7}{120}+\frac{1}{4} \zeta^{2}-\frac{1}{8} \zeta^{4}, \\
P_{s 2} & =-\frac{1}{12}+\frac{1}{2} \zeta^{2}-\frac{3}{4} \zeta^{4}-\frac{2}{5} \zeta^{5}, \\
P_{s 3} & =-\frac{1}{20}+\frac{1}{2} \zeta^{2}+\frac{2}{3} \zeta^{3}+\frac{1}{4} \zeta^{4},
\end{aligned}
$$

where $K_{s}$ is an effective eddy diffusivity.

Using these definitions of $u^{\prime}$ and $s^{\prime}$, the estuary can be described by the depth-averaged salinity as a function of time and distance along the channel. Nondimensionalizing salinity with the oceanic salinity at the open boundary $\left(s_{\mathrm{oc}}\right)$, we define $\sigma=\bar{s} / s_{\mathrm{oc}}$. The governing equation for the estuarine salt field then becomes

$$
\frac{\partial \sigma}{\partial t}=\frac{1}{A} \frac{\partial}{\partial x}\left\{-(\bar{u} \sigma A)+\left(-\overline{u^{\prime} s^{\prime}} A / s_{\mathrm{oc}}\right)+\left[K_{H}(\partial \sigma / \partial x) A\right]\right\},
$$


where $K_{h}$ is the along-channel tidal dispersion coefficient, and the $\overline{u^{\prime} s^{\prime}}$ term is the salt flux due to subtidal exchange that can be written in terms of the polynomials for $u^{\prime}$ and $s^{\prime}$. Specifically,



where term (a) is the salt flux due to gravitational circulation, terms (b) and (c) involve the depth-averaged velocity profile, and terms (d), (e), and (f) incorporate local wind effects.

The mixing coefficients, $K_{m}, K_{s}$, and $K_{h}$, all influence the longitudinal salt flux and must be parameterized. Following MacCready (2007), we assume that $K_{m}$ scales with the tidal velocity $U_{t}$ and the channel depth $H$ :

$$
K_{m}=a_{0} C_{d} U_{t} H
$$

where $C_{d}$ is a drag coefficient $\left(2.6 \times 10^{-3}\right)$ and $a_{0}$ is a tuning coefficient [0.0325 in MacCready (2007), but 0.024 to 0.028 in these results]. The drag coefficient is fixed for all cases, and only $a_{0}$ is varied to calibrate the model.

As with the eddy viscosity, the eddy diffusivity is scaled based on the $U_{t}$ and $H$,

$$
K_{s}=K_{m} / \mathrm{Sc}=\left(a_{0} C_{d} U_{t} H\right) / \mathrm{Sc},
$$

where $\mathrm{Sc}$ is a Schmidt number for the ratio of eddy viscosity to eddy diffusivity. To determine appropriate values for the mixing coefficients, $a_{0}$ and Sc were adjusted for a range of test cases and selected to maximize model skill for residual velocity and depth-averaged salinity as described in section 4 . The calibrations found $\mathrm{Sc} \sim 2.2$, compared with an effective Sc found in MacCready (2007) between 1.5 (unstratified) and 4.9 (strongly stratified).

Stratification suppresses vertical mixing, so vertical mixing coefficients decrease during periods of strong stratification. The parameterization for $K_{s}$ in MacCready (2007) accounted for stratification through a term based on a layer Richardson number and three coefficients. We propose a different approach, based on the assumption that stratification modifies the effective length scale for mixing. We hypothesize that rather than the full water depth $H$, the relevant length scale should be the height of the bottom boundary layer $h_{\mathrm{BL}}$. During unstratified periods, the boundary layer may extend to the water surface such that $h_{\mathrm{BL}}=H$. However, stratification can limit the growth of the tidal boundary layer to less than the full depth and thereby limit the size of turbulent overturns that dominate vertical mixing (Stacey and Ralston 2005).

To scale the boundary layer, we adopt a modification of the Monin-Obukhov scaling based on the estuarine buoyancy flux and assume that tidal straining of $\partial \mathrm{s} / \partial \mathrm{x}$ balances turbulent mixing at the top of the boundary layer (Stacey and Ralston 2005). The boundary layer height then is

$$
h_{\mathrm{BL}}=H\left(\frac{R_{f c}}{\mathrm{Ri}_{x}}\right)^{1 / 2},
$$

where $\mathrm{Ri}_{x}$ is the horizontal Richardson number, $\mathrm{Ri}_{x}=$ $N_{x}^{2} H^{2} /\left(C_{d} U_{t}^{2}\right), N_{x}^{2}=-g \beta(\partial \bar{S} / \partial x)$ is the horizontal buoyancy frequency, and $R_{f c}=0.2$ is the flux Richardson number relating turbulence production to mixing. When $h_{\mathrm{BL}}<H, K_{m}$ and $K_{s}$ scale with $h_{\mathrm{BL}}$ rather than $H$, decreasing vertical mixing and increasing longitudinal salt flux. When $h_{\mathrm{BL}}>H$, the limiting mixing length scale reverts to the channel depth.

The boundary layer approach assumes a linear stress distribution between the bed and $h_{\mathrm{BL}}$. In the model results, $h_{\mathrm{BL}}$ is typically less than the full water depth during neap tides while during spring tides $h_{\mathrm{BL}}$ extends to the water surface. Geyer et al. (2000) observed stress distributions in the Hudson consistent with this formulation, with near-zero stresses in the upper water column during neap tides, and stress linearly decreasing to the surface during spring tides. The scaling in (2.7) was originally derived by Stacey and Ralston (2005) for ebb tides when the horizontal buoyancy flux is stabilizing, but this length scale is intended to more generally reflect subtidal (i.e., spring-neap) variations in stratification and how the stratification impacts vertical mixing and the subtidal salt flux.

Finally, the along-channel tidal dispersion coefficient $K_{h}$ represents a combination of larger-scale dispersive processes (MacCready 2007) including stirring by lateral eddies (Banas et al. 2004) and tidal pumping at the estuary mouth (Stommel and Farmer 1952). The formulation for $K_{h}$ in the model is the same as in MacCready (2007), as we lack sufficient observations in the lower estuary to test alternative formulations. In the 

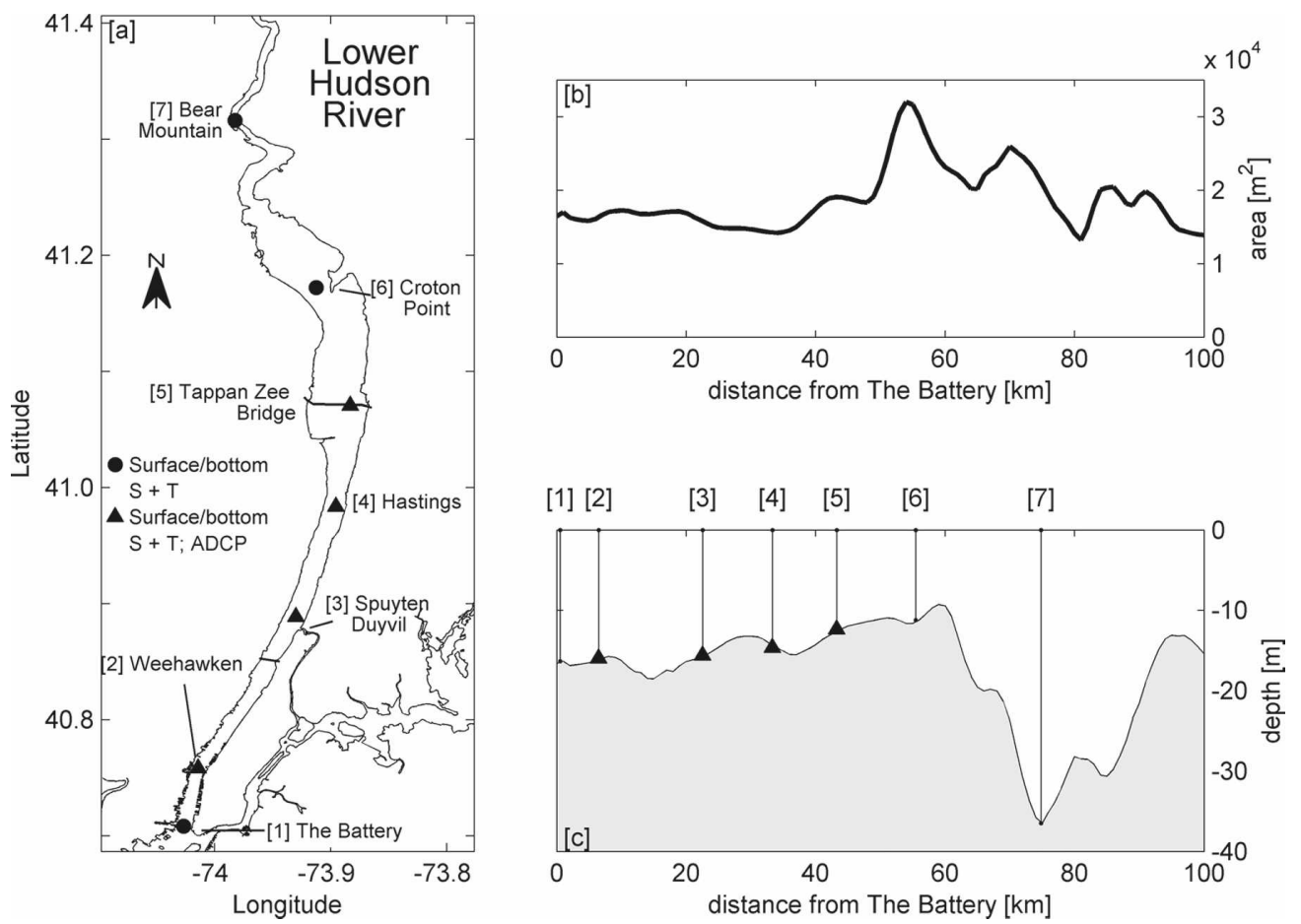

FIG. 1. Lower Hudson River map and bathymetry: (a) map with mooring locations during spring/summer 2004 deployment, (b) cross-sectional area against distance along the estuary, and (c) thalweg depth against distance along the estuary including station locations.

cases presented here, $K_{h}$ has a maximum at the mouth that can be as high as $\sim 500 \mathrm{~m}^{2} \mathrm{~s}^{-1}$ but decays to $\sim 100$ $\mathrm{m}^{2} \mathrm{~s}^{-1}$ within a tidal excursion $\left(U_{t} T_{t} / \pi\right.$, where $T_{t}$ is the tidal period). In most cases, tidal dispersion rates are lower than the flux due to the residual shear by an order of magnitude or more. The model results are consistent with observations in the Hudson that residual shear dominates the salt transport, except during spring tides with low river discharge (Hunkins 1981; Bowen and Geyer 2003; Lerczak et al. 2006).

\section{Hudson River data}

\section{a. Data sources and processing}

We compare the model with an extensive set of observations from the Hudson during spring and summer 2004 when seven moorings were deployed along the channel thalweg from the Battery (river $\mathrm{km} 0$ ) to Bear Mountain (river km 75) (Fig. 1). Four of the moorings combined bottom-mounted acoustic Doppler current profilers (ADCPs) with near-bottom and near-surface conductivity-temperature (CT) sensors. The remaining three moorings had bottom and surface CT sensors, but the surface CT sensor at the Battery station failed. Velocity and salinity measurements were taken every 15 min for 110 days.

To calculate tidal averages, salinity and velocity data were temporally averaged using a low-pass filter with a half-amplitude of $33 \mathrm{~h}$. The key variable in the model is depth-averaged salinity, but we have observations of near-bottom and near-surface salinity. In the absence of information on the vertical salinity structure, we define the depth-averaged salinity as the mean of the surface and bottom salinities. At stations with velocity measurements, tidally filtered ADCP data were depthaveraged to get the observed $\bar{u}(x, t)$. The residual velocity $u^{\prime}(x, z, t)$ is the difference between the tidally filtered velocity and $\bar{u}$. To facilitate comparison between the model and data, we calculate the effective residual velocity as the residual volume transport upestuary or down-estuary divided by the water depth. The up-estuary residual transport is equal to the downestuary transport in both the model and the observations, and normalizing by the water depth converts the residual transport to a velocity. This definition permits comparison of observed residuals with model results, even when the shape of the measured velocity profile differs significantly from the Hansen and Rattray polynomial formulation. We consider the vertical structure of the observed velocity in greater detail in section 4 . The cross-channel structure of velocity was not measured during the deployment, but previous work in the Hudson indicates that the vertical shear dominates the along-estuary salt flux (Lerczak et al. 2006). In addition 

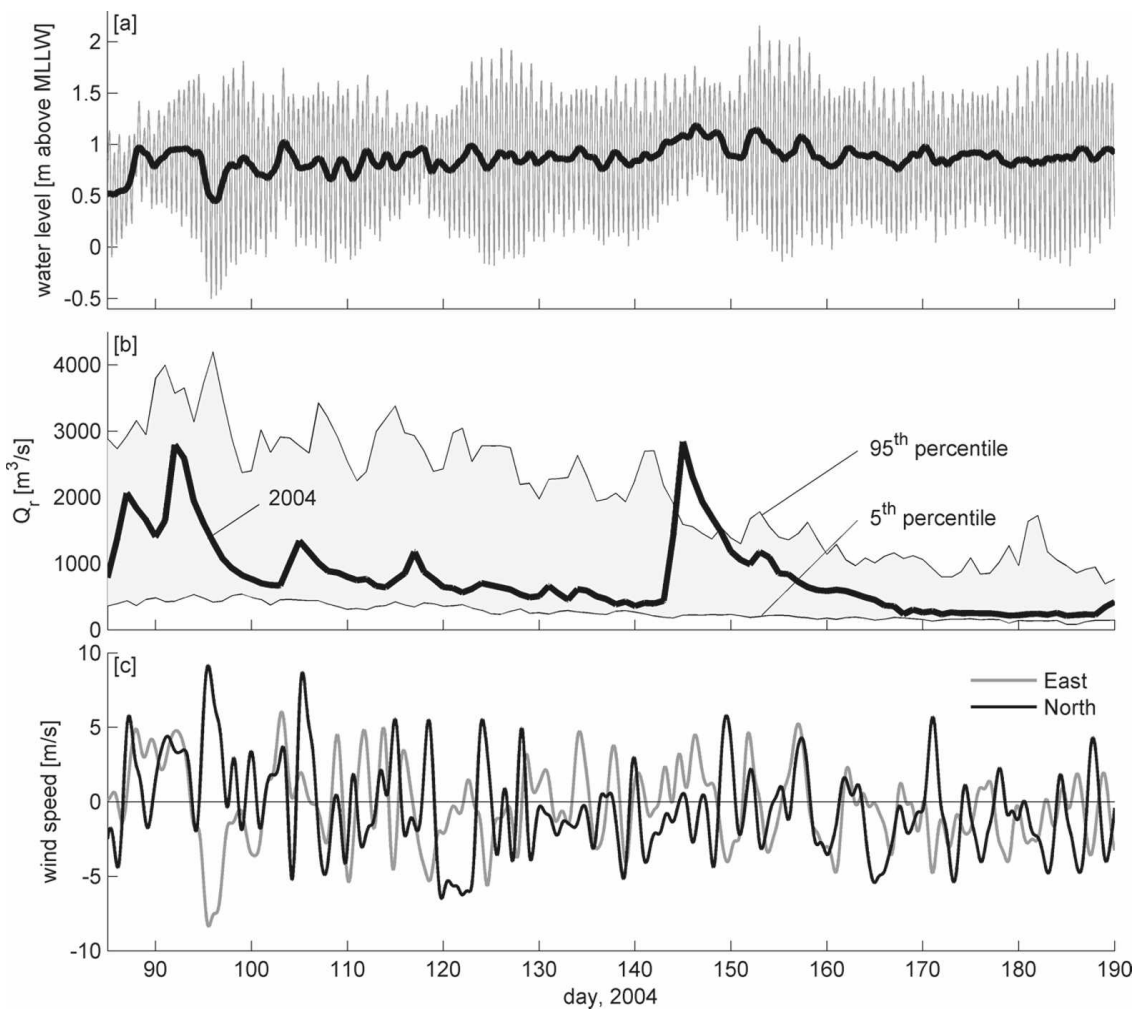

FIG. 2. Forcing conditions during spring/summer 2004 deployment: (a) instantaneous and tidally averaged water level at the Battery, (b) river discharge along with 5th and 95th percentile of daily mean discharge (1946 to 2005), (c) east and north components of wind averaged among three stations (Bergen Point, Newark, and Poughkeepsie) and tidally averaged.

to the moored instruments, along-estuary hydrographic surveys were conducted at the beginning and end of the observation period. CTD profiles were taken approximately every $2 \mathrm{~km}$ along the estuary from the Battery to where the salinity was less than 1 psu.

River discharge $\left(Q_{r}\right)$ data were collected from the U.S. Geological Survey (USGS) streamflow gauge at Green Island Dam (01358000), about $250 \mathrm{~km}$ north of the Battery (Fig. 2). To account for runoff flowing into the Hudson south of Green Island Dam, the stream gauge discharge was multiplied by a factor of 1.6 (Lerczak et al. 2006). However, $\bar{u}$ observed at the four ADCPs had significant discrepancies compared with the nominal river velocities of $Q_{r} / A$ due to meteorological band variability in $\bar{u}$ that corresponded with changes in water level at the mouth. Water levels at the Battery $\left(\eta_{\mathrm{bc}}\right)$ during the observation period were taken from a NOAA tide gauge (station 8518750) (Fig. 2). Tidal variations dominate the instantaneous water level, but the effects of coastal setup and setdown can be seen in the tidally filtered water level. Wind data were collected from several stations along the Hudson River: Bergen Point (NOAA/National Ocean Service, station 8519483), Newark Airport [National Climatic
Data Center (NCDC), station 14734], and Poughkeepsie Airport (NCDC, station 14757) (Fig. 2).

\section{b. Observations}

During the observation period, the length of the salinity intrusion in the Hudson varied by more than a factor of 2 (Fig. 3). The location of the depth-averaged, 5-psu isohaline $\left(L_{5}\right)$ varied between 28 and $75 \mathrm{~km}$ upstream of the Battery; we use $L_{5}$ to reflect the variability because it remained within the mooring array for nearly all of the deployment. Early in the deployment when river discharge was high, the length of the salinity distribution oscillated significantly each spring-neap period, with longer salinity intrusions during neaps. However, during the last three weeks of the deployment with nearly constant, low discharge, the length of the estuary remained relatively constant despite the spring-neap variability in tidal amplitude.

Like the salinity intrusion, the longitudinal salinity gradient had significant spring-neap variability during the higher discharge period (Fig. 3). The salinity gradient became more spatially uniform and temporally steady during the lower discharge period. During the higher discharge period, a zone of maximum salinity 

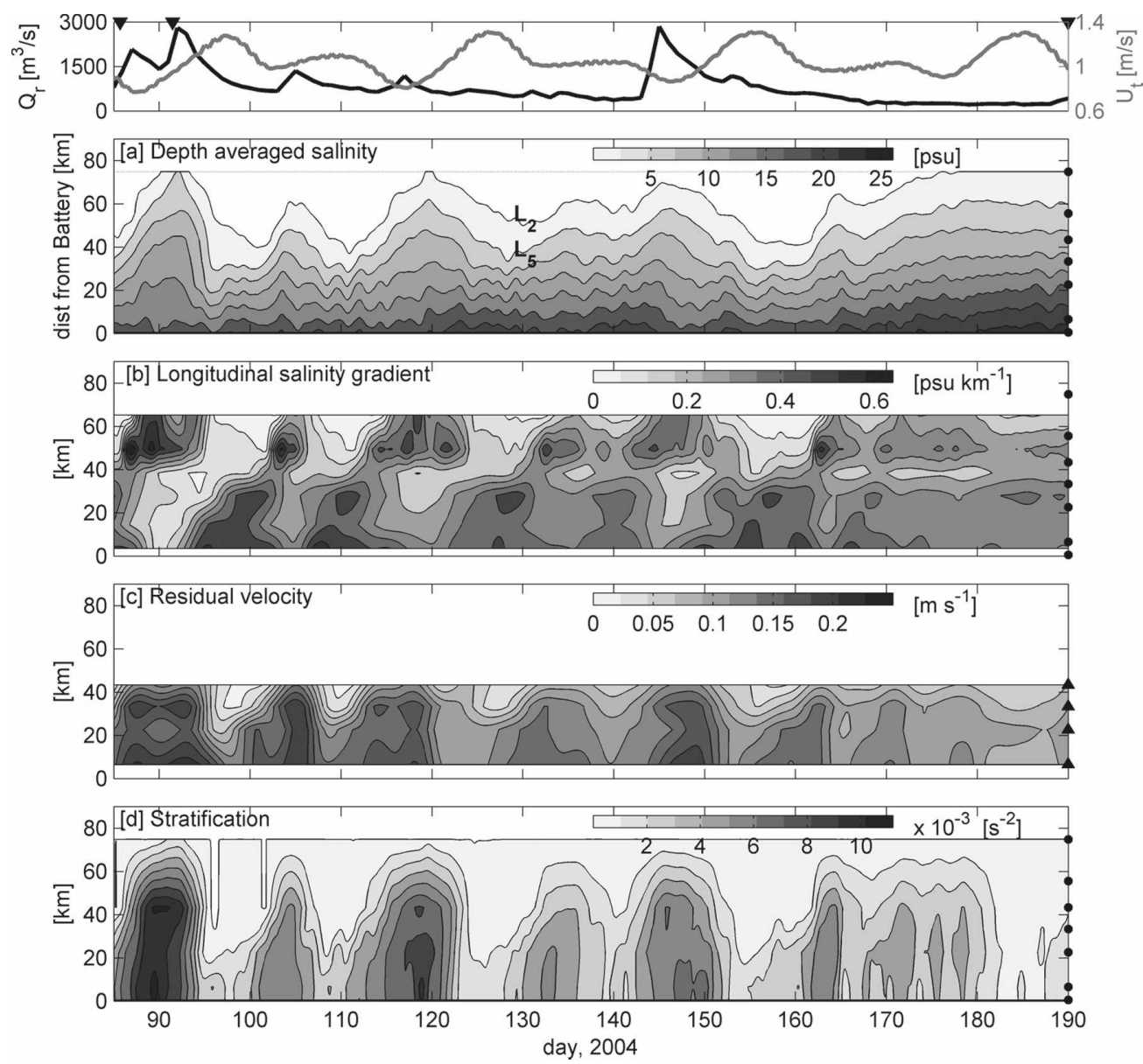

FIG. 3. Observations in the Hudson during spring/summer 2004 contoured in time and distance along the estuary: (a) average of surface and bottom salinity, (b) longitudinal salinity gradient, (c) residual velocity (low-pass filtered with a 5-day period to remove meteorological band variability), and (d) surface-to-bottom stratification. Markers in the top panel indicate times of the vertical profiles in Fig. 8. Markers on the right of each panel indicate measurement locations.

gradient propagated upstream from the mouth during transitions from spring to neap tides. As vertical mixing increased and estuarine circulation decreased during spring tides, the salinity field was rapidly advected downstream, and the maximum $\partial s / \partial x$ was reestablished at the mouth. After maximum spring tide, the cycle of $\partial s / \partial x$ propagation upstream repeated. During the higher discharge period, the surface salinity gradient was much weaker than the bottom $\partial s / \partial x$, and the spring-neap propagation up-estuary of the salinity field was most evident in the bottom $\partial s / \partial x$.

Residual velocities had significant variability at the meteorological time scale that was coherent between ADCPs, and corresponded with strong winds from the north (e.g., $t \sim 105,118$, or 149 days). To remove the synoptic variations and highlight the spring-neap and river discharge variability, we have low-pass filtered the observations with a 5-day filter period (Fig. 3). During the high discharge period, both residual velocities and stratification were significantly stronger during neap tides than during spring tides. However, unlike $\partial s / \partial x$, residual velocity and stratification were relatively uniform along the salinity distribution, at least in the region between the mouth and the maximum $\partial s / \partial x$ propagating upstream. Near the mouth, $u^{\prime}$ and $s^{\prime}$ remained large even as $\partial s / \partial x$ decreased following spring tides. This appeared to be inconsistent with the assumption that $u^{\prime}$ and $s^{\prime}$ depend on the local $\partial s / \partial x$. However, the salinity gradient measured by surface and bottom sensors may not necessarily have corresponded with the depth-integrated salinity gradient. As the system becomes more two-layer with strong stratification, salinity in the surface and bottom layers can remain relatively constant but the depth-integrated baroclinic gradient may be augmented by a landward tilt of the pycnocline. With the moored instruments, we were unable to re- 
solve the vertical structure of salinity to test this hypothesis.

During the low discharge period, both the salinity gradient and the residual velocity were more temporally steady and spatially uniform. Additionally, the surface $\partial s / \partial x$ was similar to the bottom $\partial s / \partial x$, so the moored instruments provided good estimates of the depth-integrated gradient. Stratification retained some spring-neap variability during the low discharge period, consistent with other work, suggesting that stratification responds more rapidly than estuarine length (Hetland and Geyer 2004; MacCready 2007). Unlike during the high discharge period, $\partial s / \partial x$ did not exhibit springneap propagation along the estuary.

\section{Model application}

\section{a. Model inputs}

Inputs to the model include the bathymetry $[H(x)$ and $A(x)]$, tidal velocity $\left[U_{t}(x, t)\right]$, river velocity $[\bar{u}(x, t)]$, and salinity at the open boundary $\left[s_{\mathrm{oc}}(t)\right]$. Channel depth and cross-sectional area were based on data from NOAA (http://estuarinebathymetry.noaa.gov) and from USGS surveys (Stedfast 1980). The model grid discretization is $1 \mathrm{~km}$. To define $U_{t}$, we use NOAA tidal current predictions during the observation period (http://tidesandcurrents.noaa.gov/currents04). We incorporate spatial variability in $U_{t}$ based on predicted current speed ratios (relative to the reference station at the Narrows) at 24 stations along the Hudson (http:// tidesandcurrents.noaa.gov/currents04/tab2ac4.html\#33) and interpolate between stations onto the model grid, conserving tidal volume flux. Bottom salinity at the open boundary is set according to observations at the Battery.

To extend the utility of the model, we force it with data that are independent of our observations and available over longer periods. Rather than $\bar{u}$ measured by the ADCPs, we have developed a relationship for $\bar{u}$ that depends on $Q_{r}, A$, and $\eta_{\mathrm{bc}}$. We assume that changes in water level at the downstream boundary instantaneously change the volume of the estuary and that a simple model for the associated volume flux (after Wong and Valle-Levinson 2002) is

$$
Q_{\mathrm{bc}}=A_{s} \partial\left\langle\eta_{\mathrm{bc}}\right\rangle / \partial t,
$$

where $\left\langle\eta_{\mathrm{bc}}\right\rangle$ is the subtidal water level at the Battery, and $A_{s}(x)$ is the cumulative surface area up-estuary to the dam at Green Island: $A_{s}=\int_{x}^{250 \mathrm{~km}} B_{s} d x$. The surface width is $B_{s}=\alpha A / H$, where the factor $\alpha$ relates the thalweg depth to the cross-sectional averaged depth; in the Hudson $\alpha \cong 2$. The total volume flux is the sum of the freshwater and boundary fluxes, so

$$
\bar{u}=\left(Q_{r}+Q_{\mathrm{bc}}\right) / A .
$$

Using discharge at Green Island (multiplied by 1.6 factor) and the tidal gauge at the Battery, we find good agreement between the predicted and measured $\bar{u}$, and a significant improvement over the nominal river velocity of $Q_{r} / A$ (Fig. 4).

Wind data (Fig. 2) were rotated into along- and across-estuary components based on the local orientation of the thalweg. The along-estuary component of the wind velocity was used to calculate surface wind stress according to $\tau_{w}=\rho_{a} C_{d w} U_{10}\left|U_{10}\right|$, where $\rho_{a}$ is the density of air $\left(1.2 \mathrm{~kg} \mathrm{~m}^{-3}\right), U_{10}$ is the wind speed $10 \mathrm{~m}$ above the surface, and $C_{d w}$ is a drag coefficient that depends on wind velocity (Large and Pond 1981). The orientation of the Hudson is principally north-south, so the northerly component of wind velocity dominated along-estuary wind stress.

During the study period, $Q_{r}$ ranged from nearly $3000 \mathrm{~m}^{3} \mathrm{~s}^{-1}$ after large precipitation events to about $200 \mathrm{~m}^{3} \mathrm{~s}^{-1}$ at the end of the deployment, and the 110day study covered nearly seven spring-neap cycles of varying amplitude. To compare the model against the observations, we adopt a model skill definition (Wilmott 1981) previously used to evaluate a three-dimensional hydrodynamic model of the Hudson River estuary (Warner et al. 2005):

$$
\text { Skill }=1-\frac{\sum\left|X_{\text {model }}-X_{\text {obs }}\right|^{2}}{\sum\left(\left|X_{\text {model }}-\overline{X_{\text {obs }}}\right|+\mid X_{\text {obs }}-\overline{X_{\text {obs }}}\right)^{2}},
$$

where $X$ is the variable being evaluated and the overbar is a temporal mean. Other model skill metrics are possible, but this approach permits comparison of results with an existing model of the Hudson.

We present several versions of the model to evaluate the modifications independently: boundary forcing effects on $\bar{u}$, wind effects on $u^{\prime}$ and $s^{\prime}$, and boundary layer limitations on the vertical mixing coefficients (Table 1). In each case, the primary tuning parameter is $a_{0}$ to set $K_{m}$ and $K_{s}$. Increasing $a_{0}$ generates stronger vertical mixing, decreases estuarine circulation, decreases stratification, and leads to a shorter estuary. The cases were run for a series of $a_{0}$, and optimal values were selected based on the maximum skill for residual velocity. In cases $\mathrm{A}$ through $\mathrm{D}$, independent calibrations found the same $a_{0}$ of 0.024 , while case $\mathrm{E}$ with the boundary layer mixing length had a slightly higher $a_{0}$ of 0.028 . The salt flux also depends on the Schmidt number to set $K_{s}$, so Sc was calibrated to maximize skill for depth-averaged salinity. For all of the cases, the optimal Sc was found to be approximately 2.2. 

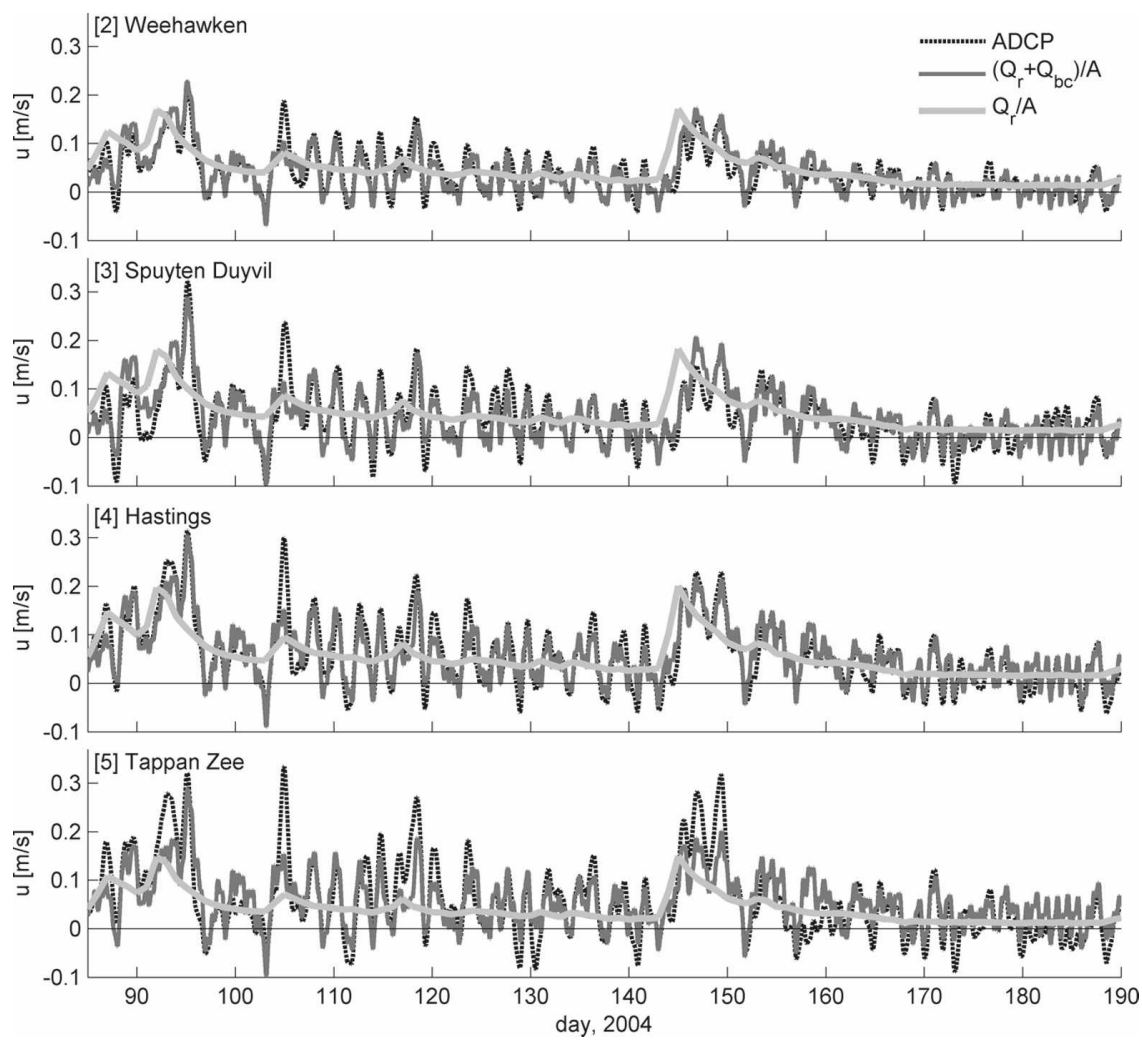

FIG. 4. Subtidal, depth-averaged velocity at four stations, including velocity measured at the ADCPs, velocity calculated based on $Q_{r}$ and boundary volume fluxes associated with the subtidal water level at the Battery, and velocity calculated based only on $Q_{r}$.

\section{b. Model results}

Initially, we focus on results from two cases, the base case (case A) and the final case (case E), which includes the boundary forcing effects on $\bar{u}$, wind effects on $u^{\prime}$ and $s^{\prime}$, and bottom boundary layer constraints on mixing length scale. Considering first residual velocity, the modeled $u^{\prime}$ from case A captures much of the low frequency modulation in the observed $u^{\prime}$, but there is significantly less higher frequency variability in the model than in observations (Fig. 5). The meteorological band variability in the residual velocity was due to the alongestuary wind, and the results from case E track those fluctuations largely because of the addition of wind to the formulations for $u^{\prime}$ and $s^{\prime}$. Case $\mathrm{E}$ also includes modifications to $\bar{u}$ and the mixing formulation but, as we discuss later with the model skill, the critical modification for improvement of $u^{\prime}$ was the addition of local wind effects.

Depth-averaged salinity is the state variable in the model, but to compare with observations we have calculated the surface and bottom salinities $\left(s_{s}\right.$ and $\left.s_{b}\right)$ that result from $s^{\prime}$ profiles in the model (Fig. 6). Both cases generally tracked the observed salinity, particularly during the low $Q_{r}$ period late in the deployment. During this low discharge period, salinity at each station increased during the neap, as the intrusion slowly moved up estuary, and then stabilized as tidal mixing increased during the spring tide and estuarine exchange decreased ( $t>182$ day). However, differences between cases $\mathrm{A}$ and $\mathrm{E}$ were more apparent during higher discharge conditions early in the deployment. Case A significantly underpredicted the temporal variability in salinity and in the length of the estuary during the higher discharge period. In the observations, midestuary sa-

TABLE 1. Outline of model cases, with modifications included in each case and the resulting optimal tuning parameters, $a_{0}$.

\begin{tabular}{lcccc}
\hline \hline \multicolumn{1}{c}{ Case } & $\begin{array}{c}\text { u }= \\
f\left(Q_{\mathrm{bc}}\right)\end{array}$ & $\begin{array}{c}u_{e}= \\
f\left(\tau_{w}\right)\end{array}$ & $\left\{\begin{array}{r}\left.\text { (K } K_{m}, K_{s}\right\}= \\
f\left(h_{\mathrm{BL}}\right)\end{array}\right.$ & $a_{0}$ \\
\hline A: Base & & & & 0.024 \\
B: $\bar{u}$ & $\bullet$ & & & 0.024 \\
C: $u_{w}$ & & $\bullet$ & & 0.024 \\
D: $\bar{u}+u_{w}$ & $\bullet$ & $\bullet$ & & 0.024 \\
$\mathrm{E}: \bar{u}+u_{w}+K_{m \mathrm{BL}}$ & $\bullet$ & $\bullet$ & $\bullet$ & 0.028 \\
\hline
\end{tabular}




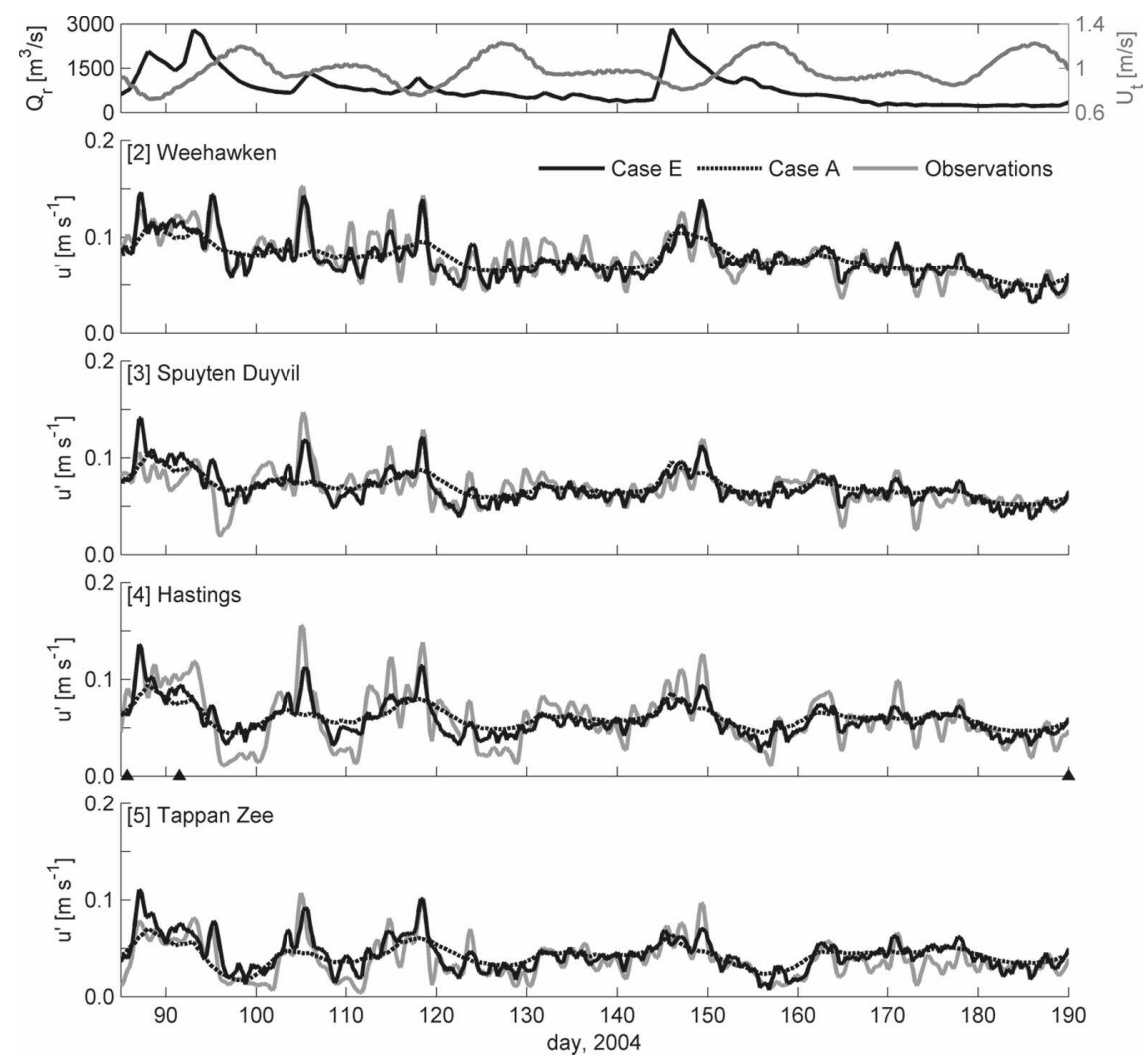

FIG. 5. Residual velocity at four stations, with observations and model results for cases $\mathrm{E}$ and A. Markers in the fourth panel indicate times of the vertical profiles in Fig. 8.

linities (e.g., Hastings or Tappan Zee stations) were higher during high discharge neaps (e.g., $t \sim 92,120$, 150 days) and lower during high discharge springs (e.g., $t \sim 112$ and 128 days) than predicted by the model. Case A could be tuned to yield higher skill during the high discharge period by decreasing $a_{0}$, but doing so degraded model skill during the low discharge period and decreased the overall skill. Lower $a_{0}$ during high $Q_{r}$ is consistent with reduced vertical mixing due to increased stratification. A correlation between increased $Q_{r}$ and decreased tidally averaged mixing has been proposed as a mechanism for damping the response of the salinity distribution to $Q_{r}$ in northern San Francisco Bay (Monismith et al. 2002).

For case E, the value for $a_{0}$ did not change whether the skill was optimized for the high discharge period or for the entire simulation. With a single value for $a_{0}$, case E captured more of the salinity variability at the springneap time scale as well as at meteorological time scales. For example, during the first high discharge period $(t \sim 87$ to 96 days), the near-bottom salinity initially increased despite increased $Q_{r}$. Several factors contributed to the up-estuary transport of salt: strong winds predominantly from the north reinforced the estuarine residual velocity, sea level setup at the Battery delayed the increase in $\bar{u}$ until after the peak in $Q_{r}$, and stratification due to the increased $Q_{r}$ and neap tidal velocities decreased vertical mixing. The dependence of tidally averaged mixing on $\mathrm{Ri}_{x}$ allowed case $\mathrm{E}$ to better predict the salinity distribution during both high and low discharge periods. The boundary layer parameterization incorporates changes in both river discharge and tidal forcing through $\mathrm{Ri}_{x}$, varies spatially with bathymetry, and adapts the scaling for vertical mixing to a physically relevant length scale.

While case $\mathrm{E}$ improves the spring-neap variability in salinity during the high discharge period, there were still significant discrepancies between the modeled and observed salinities, particularly at the up-estuary stations. During the high discharge period, salinity in the model responded too quickly to increases in tidal amplitude at transitions from neap to spring tides. In the model, responses were largely in phase with the tidal amplitude, and the salt field began to retreat when tidal amplitude increased after the neap minimum. In the observations, the salinity at a station continued to increase for a day or two after the neap minimum in tidal amplitude before the salinity intrusion began to retreat 

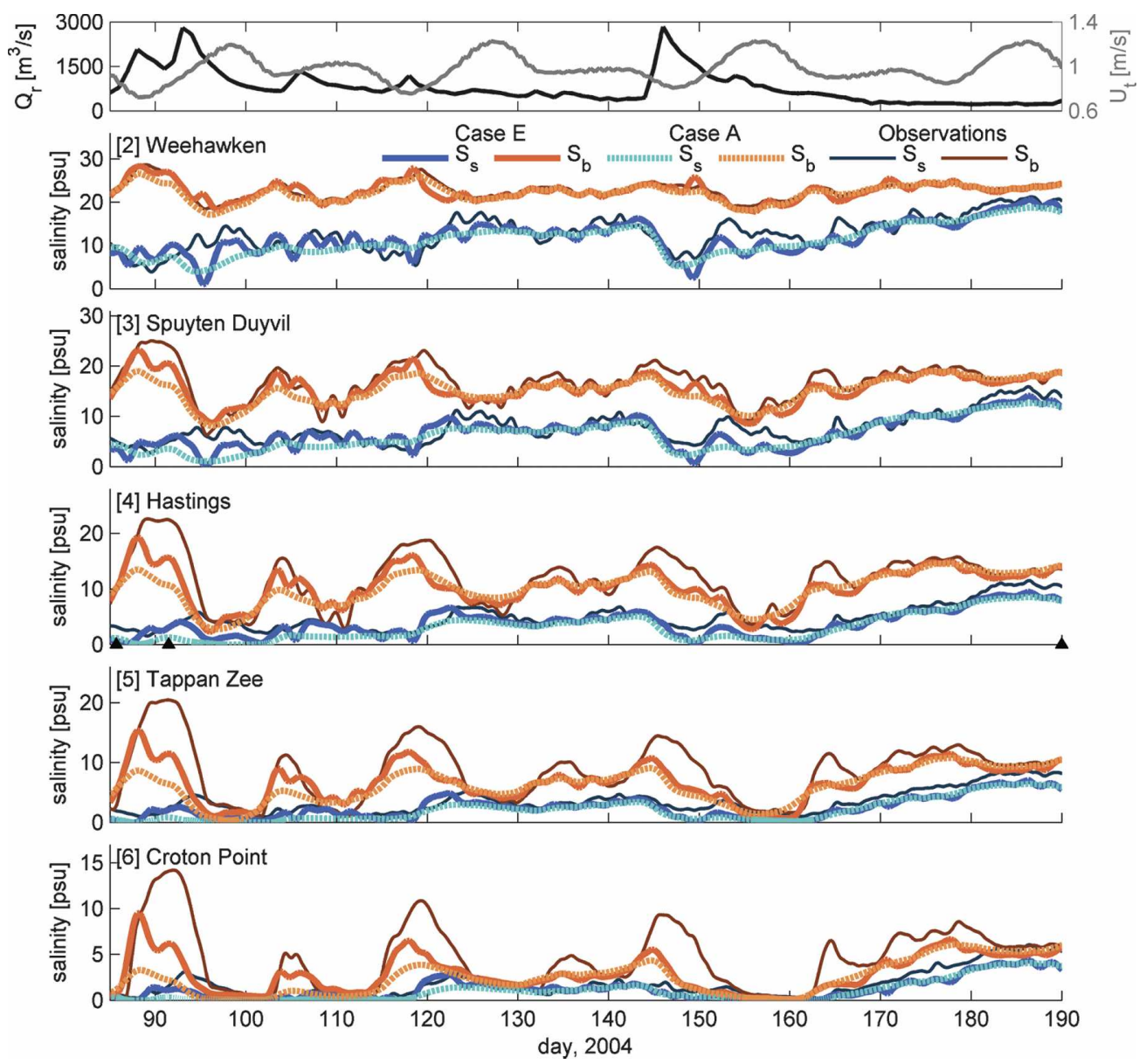

FIG. 6. Surface and bottom salinity at five stations, with observations and model results for cases E and A. Markers in the fourth panel indicate times of the vertical profiles in Fig. 8.

(e.g., $t \sim 92$ or 120 days), and bottom salinities significantly exceeded the model values at the up-estuary locations. The lag between bottom salinity response and tidal amplitude in the observations could be related to the time required to mix away stratification at the end of the neaps, while the model assumes that mixing depends on the instantaneous $U_{t}$. Discrepancies between the model and data are particularly apparent after very weak neap tides and during periods of moderate to high river discharge. These conditions are most conducive to strong stratification and transition toward a two-layer estuary, which as we discuss later, stretches the limits of applicability of the model.

The $\partial s / \partial x$ observed between surface measurements were significantly lower than between bottom measurements, particularly during the high discharge period. In the model, only the depth-averaged gradient is considered and it generally fell midway between the observed surface and bottom gradients (Fig. 7). Again we use the $s^{\prime}$ profiles to calculate implied bottom and surface sa- linity gradients and see that the model reproduced some, but not all, of the temporal variability in the observations. For example, the local maximum in bottom salinity gradient propagated upstream following spring tide maxima in $U_{t}$ during high $Q_{r}$ (e.g., $t \sim 96$ to 103 days, or 155 to 162 days). However, during high discharge neaps, the model tended to overpredict $\partial s / \partial x$ in the lower estuary. At these times the salinity intrusion extended far up-estuary, and the observed bottom $\partial s / \partial x$ near the mouth was relatively weak.

We compare the residual velocity and salinity profiles used in the model with observations over a range of river discharge conditions (Fig. 8). Residual velocities were from an ADCP midestuary (station 4, Hastings), but results were similar at other locations. Salinity profiles were individual casts at the beginning and end of the deployment, but tidally averaged surface and bottom salinities from the mooring have been plotted for reference. The three times shown have similar tidal forcing $\left(U_{t} \sim 0.9\right.$ to $\left.1.0 \mathrm{~m} \mathrm{~s}^{-1}\right)$, but range in river dis- 


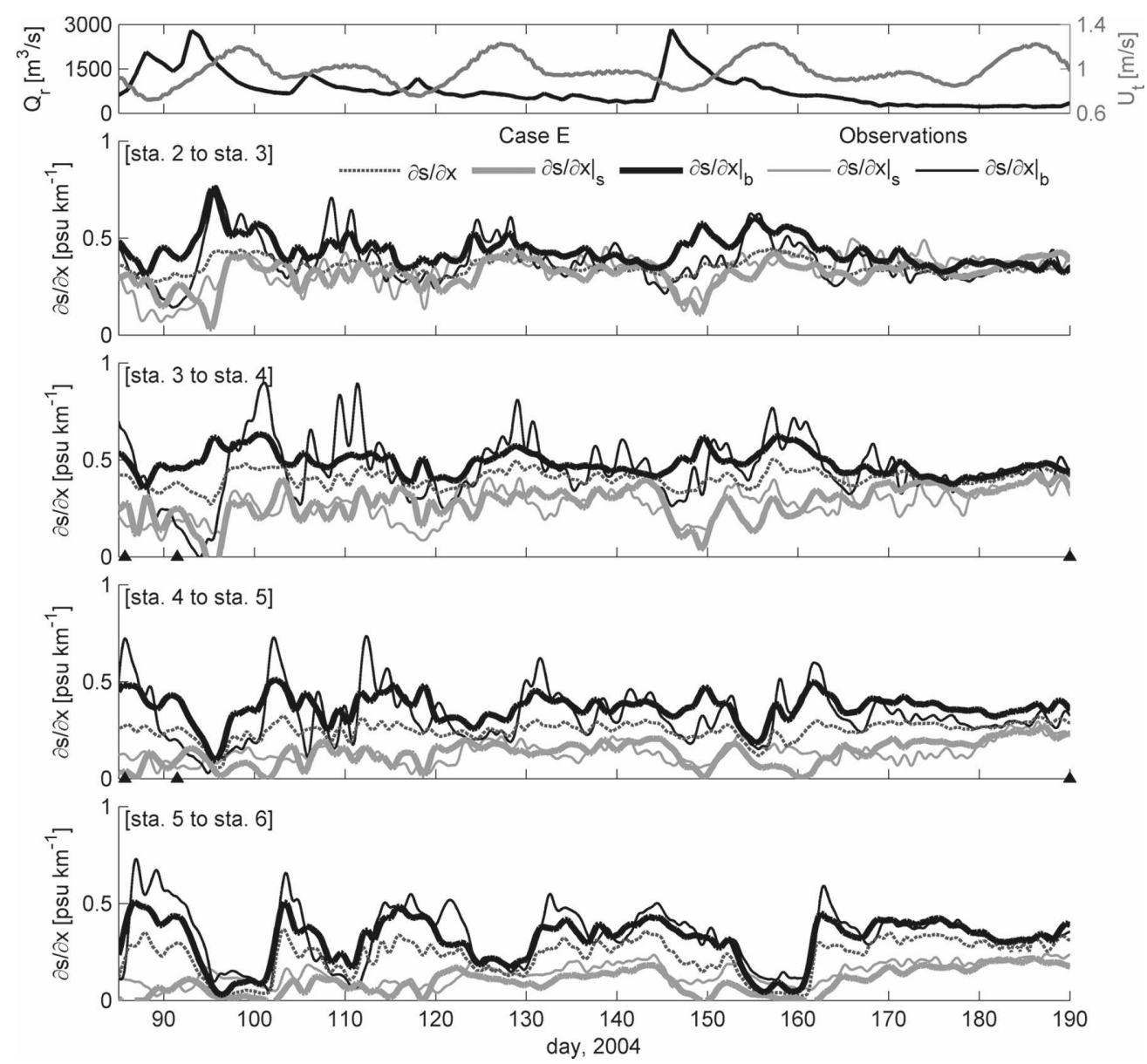

FIG. 7. Longitudinal salinity gradients between stations, with depth-averaged model results for case E, surface and bottom salinity gradients implied from the model, and surface and bottom salinity gradients from observations. Markers in the third and fourth panels indicate times of the vertical profiles in Fig. 8.

charge from 400 to $2200 \mathrm{~m}^{3} \mathrm{~s}^{-1}$. In addition to observed and model profiles, we have plotted $u^{\prime}$ and $s^{\prime}$ calculated from Eqs. (2.1) and (2.2) using the observed $\partial s / \partial x$ with and without contributions from the wind and river velocity. Differences between these calculations and the model profiles occur because $\partial s / \partial x$ is part of the model solution and does not necessarily correspond with the observed $\partial s / \partial x$. Note that the mean of the observed $\partial s_{s} / \partial x$ and $\partial s_{b} / \partial x$ do not necessarily correspond with the depth integral of $\partial s / \partial x$ and, in fact, may be very different during high discharge periods as we discuss later.

The velocity profiles indicate both the improvements and limitations of the model modifications. In the examples during low and moderate discharge, both the model and the estimates using the measured $\partial s / \partial x$ matched the observations well. In the high discharge example ( $t=92$ days), inclusion of wind effects and the boundary layer mixing parameterization (case E) significantly improved the fit. The wind effects are in- cluded in the profiles calculated from observed $\partial s / \partial x$ and $\tau_{w}$, but the model results were closer to matching the observations because $\partial s / \partial x$ in the model was greater than average of $\partial s_{s} / \partial x$ and $\partial s_{b} / \partial x$ at the moorings. Although the magnitude of $u^{\prime}$ in the model corresponded well with the observations, the shape of the profile was very different. During the high discharge period, a relatively thin, sheared surface layer overlay a thicker bottom layer with nearly constant velocity near the bed and an up-estuary velocity maximum at approximately middepth. The Hansen and Rattray polynomials do not incorporate the more complex residual shear structure (or corresponding stratification profiles, but we lack salinity profiles during this period for comparison).

To quantitatively compare the different cases, we calculate model skill for output variables as a function of distance along the estuary, including depth-averaged salinity, surface-to-bottom stratification, and residual 

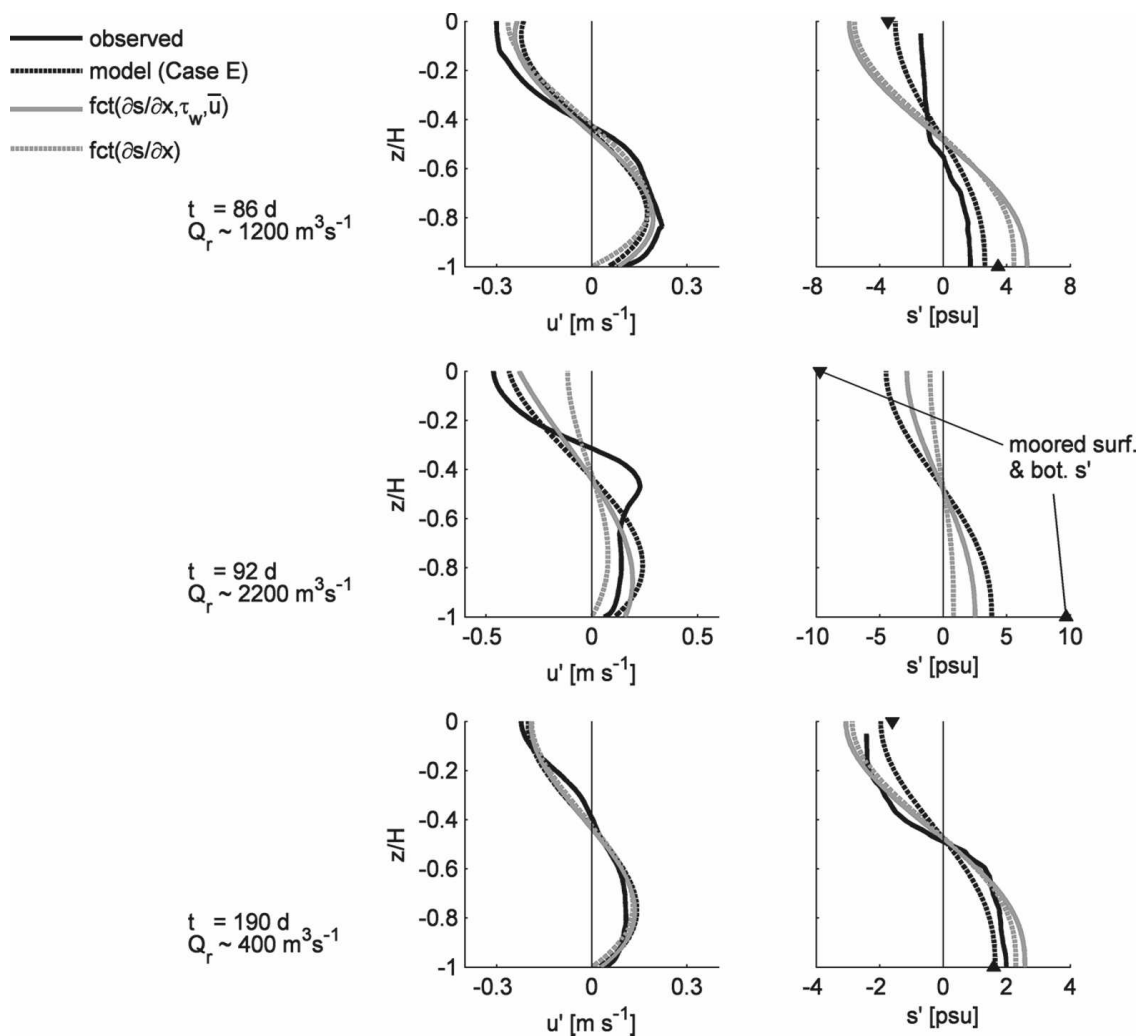

FIG. 8. Three examples of vertical profiles of residual velocity and salinity at Hastings (station 4): at deployment with moderate discharge $\left(Q_{r} \sim 1200 \mathrm{~m}^{3} \mathrm{~s}^{-1}\right), 6$ days later with higher discharge $\left(Q_{r} \sim 2200 \mathrm{~m}^{3} \mathrm{~s}^{-1}\right)$, and at recovery with lower discharge $\left(Q_{r} \sim 400 \mathrm{~m}^{3} \mathrm{~s}^{-1}\right)$. Observations, model results (case E), and Hansen and Rattray scaling according to the measured $\partial s / \partial x, \tau_{w}$, and $\bar{u}$ are plotted. Observed salinity profiles are individual casts, but tidally averaged moored surface and bottom salinities are plotted for reference.

velocity (Fig. 9). Additionally, we present the skill at predicting isohaline position along the estuary as a function of salinity. For reference, we include the skill for these parameters in a hydrodynamic model of the Hudson in which salinity and velocity were evaluated $23 \mathrm{~km}$ north of the Battery over a 40-day period with $Q_{r}$ ranging from about 300 to $2000 \mathrm{~m}^{3} \mathrm{~s}^{-1}$ (Warner et al. 2005). Generally, predictive skill decreased with distance from the Battery. Comparing the different cases, model skill improved for all parameters with the modifications. Depth-averaged salinity, stratification, and estuary length were most affected by the shift to the boundary layer mixing parameterization. Residual velocity was most sensitive to inclusion of the wind forcing to capture the metrological band variability. Skill was lowest for stratification at up-estuary locations, a deficiency related in part to the model's poor representation of the spring-neap propagation of the salinity field up the estuary. Case E had the highest skill for all the variables among the different model runs, but all cases compared favorably with the hydrodynamic model. The skill of the one-dimensional model is optimized by the tuning of two parameters $\left(a_{0}\right.$ and Sc), but generally the magnitude and spatial and temporal variability of the results compare well with observations over a wide range of forcing conditions.

\section{Equilibrium and response}

The time-dependent response of an estuary can significantly depart from the equilibrium salinity distribution for a set of forcing conditions (MacCready 1999; Hetland and Geyer 2004; MacCready 2007; LGR). If estuarine exchange dominates the upstream transport, the steady-state salt budget can be approximated as a balance between mean advection and gravitational circulation (Hansen and Rattray 1965; MacCready 1999; Monismith et al. 2002). Based on this balance, a salt intrusion length scale $L_{x}$ can be written (following Monismith et al. 2002) as 

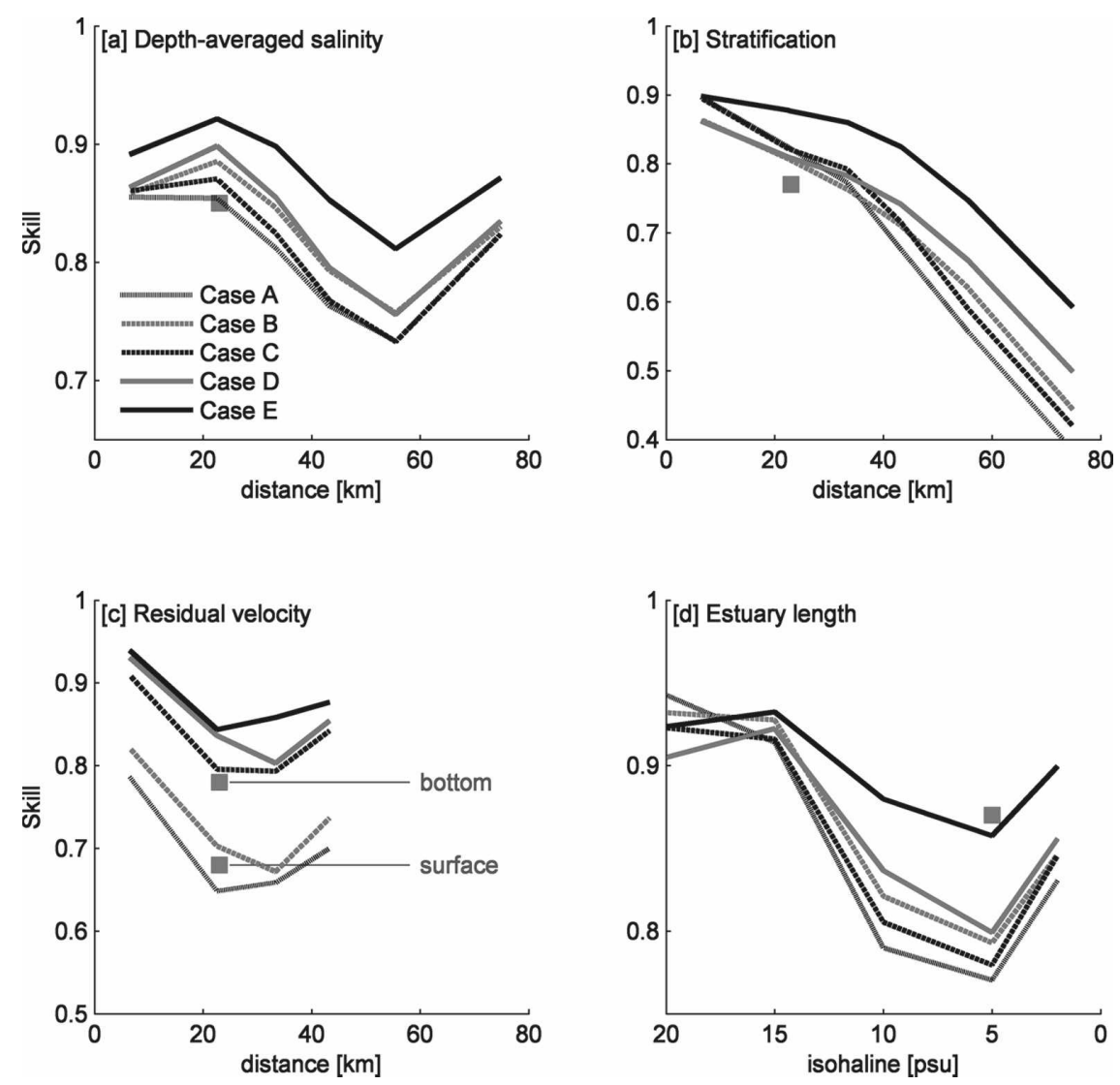

FIG. 9. Model skill [Eq. (4.3)] for (a) depth-averaged salinity, (b) surface-to-bottom stratification, (c) residual velocity (all against distance along the estuary), and (d) estuary length (isohaline location as a function of salinity). Square markers are skills from a threedimensional hydrodynamic model of the Hudson evaluated $23 \mathrm{~km}$ from the Battery and for the 5-psu isohaline (Warner et al. 2005).

$$
L_{x} \sim \frac{\left(\beta g S_{0}\right)^{2 / 3} A^{1 / 3} H^{5 / 3}}{\gamma Q_{r}^{1 / 3} U_{t}},
$$

where $\gamma=\left(a_{0} C_{d} \mathrm{Sc}^{-1 / 3}\right)$ is a constant from the vertical mixing parameterization. Note that, in addition to assuming $K_{h} \sim 0$, this balance requires that $\bar{u} \ll u_{e}$ so that the contributions to $\overline{u^{\prime} s^{\prime}}$ from $\bar{u}$ are negligible. This scaling yields $Q_{r}^{-1 / 3}$ proportionality for estuary length and indicates that $L_{x}$ scales inversely with tidal forcing $\left(U_{t}^{-1}\right)$. We can also define the dependence of $L_{x}$ on channel depth and cross-sectional area as a geometric factor $G=A^{1 / 3} H^{5 / 3}$ : $G$ is constant for an idealized uniform cross section but varies with the location of the salinity intrusion in real estuaries.

To compare the time-dependent Hudson model with equilibrium conditions, we allowed the salinity distribution to reach steady state for a range of $Q_{r}$ and $U_{t}$. The equilibrium model results do not depend on the wind or open boundary forcing of $\bar{u}$, but we tested both mixing parameterizations, the base case $\left(K_{m 0}\right)$ and the
$h_{\mathrm{BL}}$ mixing length case $\left(K_{m \mathrm{BL}}\right)$. The average location of the 2-psu isohaline $\left(L_{2}\right)$ for each $Q_{r}$ is plotted, with vertical lines indicating the spread of results for different $U_{t}$ (Fig. 10).

With $K_{m 0}$ or with $K_{m \mathrm{BL}}$, equilibrium estuary lengths for the Hudson scaled roughly as $Q_{r}^{-1 / 3}$, and the effect of stratification on mixing (through $h_{\mathrm{BL}}$ ) had only a minor impact on the relationship between $Q_{r}$ and $L_{2}$. As was proposed by Monismith et al. (2002), stratification during periods of high river discharge suppresses vertical mixing, enhancing upstream salt flux, and reducing the sensitivity of the salinity field to increases in $Q_{r}$. With increased river discharge, both $\partial s / \partial x$ and $\mathrm{Ri}_{x}$ increase, decreasing $h_{\mathrm{BL}}$ and decreasing vertical mixing, and increasing $u_{e}$. Based on a regression fit of the model results, the power-law exponent for the scaling decreases from $L_{x} \sim Q_{r}^{-0.40}$ for $K_{m 0}$ to $L_{x} \sim Q_{r}^{-0.35}$ with $K_{m \mathrm{BL}}$ (Table 2). Following an approach similar to that for (5.1), the expected scaling using $K_{m \mathrm{BL}}$ is $L_{x} \sim Q_{r}^{-2 / 9}$, a salinity intrusion less sensitive to discharge than $Q_{r}^{-1 / 3}$ 


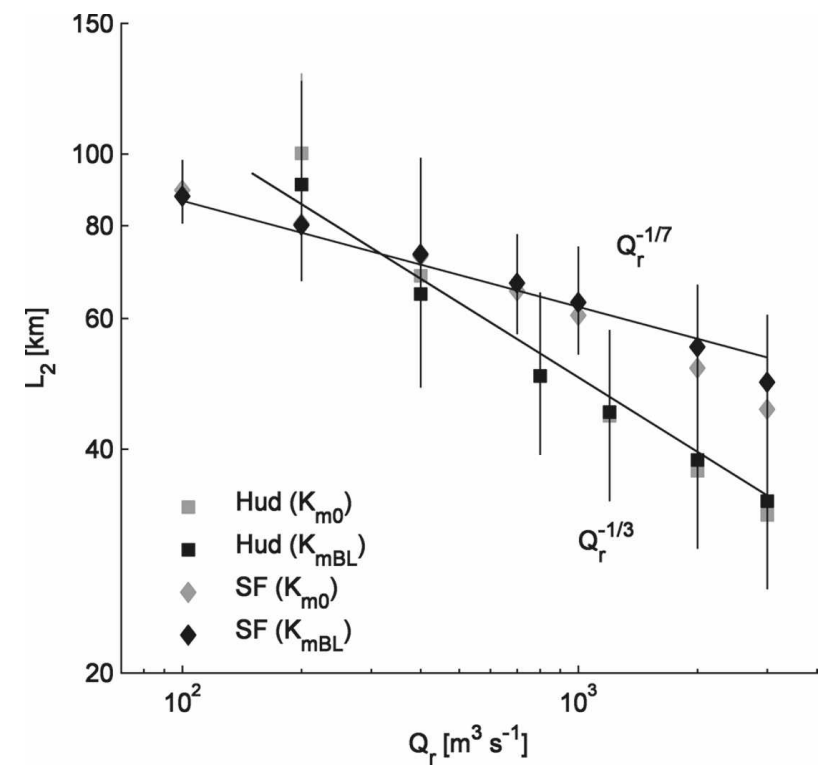

FIG. 10. Modeled equilibrium salinity intrusion as a function of $Q_{r}$ and $U_{t}$ in the Hudson and northern San Francisco Bay based on the location of the 2-psu isohaline $\left(L_{2}\right)$ for the base mixing case $\left(K_{m 0}\right)$ and for the boundary layer mixing case $\left(K_{m \mathrm{BL}}\right)$. Markers are averages at a given $Q_{r}$, and vertical lines represent the range of $L_{2}$ depending on $U_{t}$.

(LGR). Effectively, both mixing parameterizations are consistent with observations that $L_{0.1} \sim Q_{r}^{-0.38}$ for low to moderate discharge in the Hudson (Abood 1974; Wells and Young 1992). The model did not return exactly the theoretical scaling relationships because it incorporated Hudson bathymetry rather than a uniform cross section, retained the complete representation of $\overline{u^{\prime} s^{\prime}}$ (including the contribution of $\bar{u}$ ), and had nonzero $K_{h}$. These factors also confound our ability to distinguish between the equilibrium responses of the two mixing schemes in the Hudson and other estuaries.

In addition to the Hudson, we have applied the model to northern San Francisco Bay using the bathymetry and salinity open boundary condition from Monismith et al. (2002). As noted by MacCready (2004, 2007), the model reproduces the equilibrium relationship of $L_{x} \sim Q_{r}^{-1 / 7}$ observed there (Monismith et al. 2002), indicating that the salinity intrusion is less sensitive to river discharge than the classical $Q_{r}^{-1 / 3}$ scaling (Fig. 10). Note that we have increased slightly the $a_{0}$ coefficients for San Francisco Bay to correspond with the empirical fit of $L_{2}=167 Q_{r}^{-0.141}$ (Monismith et al. 2002): $a_{0}=0.032$ for $K_{m 0}$ and $a_{0}=0.036$ for $K_{m \mathrm{BL}}$.

Monismith et al. (2002) attributed the observed $Q_{r}^{-1 / 7}$ dependency to stratification reducing vertical mixing and increasing estuarine circulation, effectively stiffening the salinity field to increases in river discharge. The authors proposed that the factor $\gamma$ modifying the tidally
TABLE 2. Equilibrium model results for the power-law fit between river discharge and estuarine length (location of 2-psu isohaline) as well as the geometric factor $G$. Results are presented for cases with and without the boundary layer mixing-length-scale parameterization for both Hudson River and northern San Francisco Bay.

\begin{tabular}{ccc}
\hline \hline \multicolumn{3}{c}{ Scaling of $L_{x}(2 \mathrm{psu})$} \\
\hline \multicolumn{3}{c}{$L_{2} \sim Q_{r}^{n}$} \\
$n_{Q}$ & $\bar{G} \sim Q_{r}^{n_{G}}$ \\
$n_{G}$ \\
$K_{m 0}$ & Hudson \\
$K_{m \mathrm{BL}}$ & -0.40 & -0.004 \\
& -0.35 & -0.005 \\
$K_{m 0}$ & San Francisco Bay & \\
$K_{m \mathrm{BL}}$ & -0.20 & 0.190 \\
\hline
\end{tabular}

averaged vertical mixing coefficient in Eq. (5.1) should depend on $Q_{r}$. The range of $\gamma$ from Monismith et al. (2002) produced a range of variability in mixing comparable to the $K_{m \mathrm{BL}}$ parameterization here. When the San Francisco Bay bathymetry was run with the $K_{m \mathrm{BL}}$ mixing formulation, the sensitivity of the salinity intrusion to $Q_{r}$ decreased slightly from $Q_{r}^{-0.20}$ to $Q_{r}^{-0.17}$, but both $K_{m 0}$ and $K_{m \mathrm{BL}}$ cases were closer to the observed $Q_{r}^{-1 / 7}$ than to the $Q_{r}^{-1 / 3}$ of the Hudson.

Whereas we corroborate the $L_{2} \sim Q_{r}^{-1 / 7}$ relationship, our analysis indicates that the dominant reason that the salinity intrusion in northern San Francisco Bay is less sensitive to changes in discharge is because of the bathymetry rather than stratification. As discharge increases, the salinity field is pushed downstream toward the Golden Gate where $H$ and $A$, and therefore $G$, are much greater (Fig. 11). Greater depth increases residual salt transport $\left(\sim H^{8}\right)$, and greater area decreases $\bar{u}$. To calculate an effective $G$ that reflects the position of the salinity field for each set of forcing conditions, we use a spatial average weighted by $\partial s / \partial x: \bar{G}=\int G(\partial s / \partial x)$ $d x / \int(\partial s / \partial x) d x$, where the integral spans the length of the estuary. Rather than averaging over the entire estuary, we have normalized $\bar{G}$ by $\partial s / \partial x$ because the bathymetric parameters should reflect where the salt flux occurs. Over the typical range of the salinity intrusions in the Hudson, $\bar{G}$ changes relatively little with $Q_{r}$ (Table 2). However, in San Francisco Bay, the dependence of the effective bathymetry on discharge is pronounced, with $\bar{G} \sim Q_{r}^{0.17}$. Combining this geometric effect with the classical $Q_{r}^{-1 / 3}$ scaling yields an overall dependence of $L_{x} \sim Q_{r}^{0.17-0.33} \sim Q_{r}^{-0.16}$, similar to the observed $Q_{r}^{-1 / 7}$ and the model results. Alternatively, modeled salinity intrusions in both the Hudson and San Francisco Bay can be linearly scaled by the factor $\bar{G} Q_{r}^{-1 / 3} U_{t}^{-1}$ (Fig. 11). While stratification has a moderate effect on the $Q_{r}$ scaling in both estuaries, the dom- 

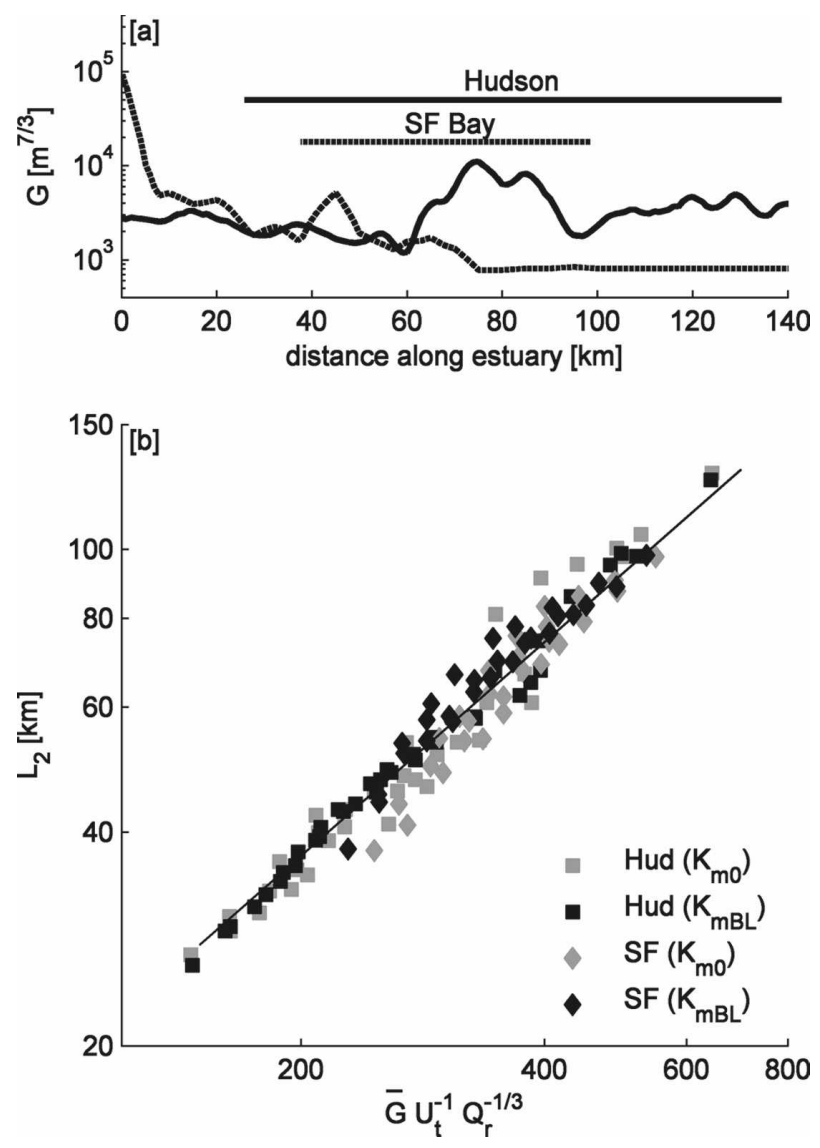

FIG. 11. Scaling the modeled equilibrium salinity intrusions in the Hudson and northern San Francisco Bay for the base mixing case $\left(K_{m 0}\right)$ and for the boundary layer mixing case $\left(K_{m \mathrm{BL}}\right)$ : (a) geometric factor $G$ as a function of distance along estuary (horizontal lines indicate range of $L_{2}$ for the discharges tested here); (b) $L_{2}$ as a function of the scaling factor $\left(\bar{G} U_{T}^{-1} Q_{r}^{-1 / 3}\right)$.

inant contributor to the observed $Q_{r}^{-1 / 7}$ relationship in San Francisco Bay appears to be the along-estuary variability in bathymetry.

\section{Discussion}

Despite simplifications in the lateral and vertical dimensions, the time-dependent, one-dimensional model reproduced observed subtidal salinity distributions and residual velocities in the Hudson River over a wide range of forcing conditions. The model works because salt flux due to gravitational circulation is much greater than tidal dispersion in much of the estuary, and a Hansen and Rattray-style parameterization offers an effective means of representing the residual flux. The original version of the model conveyed the bulk characteristics of the estuary, reproducing the mean salinity intrusion and mean residual velocity. Temporal evolu- tion in the model is critical, as steady-state salinity distributions that assume the estuary is in equilibrium with the instantaneous $Q_{r}$ and $U_{t}$ provide very poor estimates of actual salinity fields. Steady-state scaling does not take into account the response time of the estuary relative to forcing variability. Even during periods with relatively constant $Q_{r}$, the estuary rarely adjusted to its equilibrium length because of the spring-neap variability in tidal amplitude.

The base case performed best during low river discharge conditions but deviated significantly from the observations during moderate to high discharge and weak tidal mixing. Incorporating effects of stratification on vertical mixing through the height of the bottom boundary layer increased the sensitivity of the system to variability in $U_{t}$ and slightly decreased the sensitivity to $Q_{r}$. The modification was most notable during high discharge periods when estuarine response times were short enough that spring-neap variability in $U_{t}$ transmitted into changes in estuary length. Alternative formulations for effects of stratification on mixing are possible, and the original formulation using tidally averaged stratification (MacCready 2007) produced results with skills that were lower but not substantially so. Within the limits of these observations, it is difficult to definitively establish the more accurate approach, but we selected the $h_{\mathrm{BL}}$ formulation because it is based on a physically relevant length scale and depends on fewer unknown parameters.

The modifications incorporating local and remote wind effects were particularly important during large storms, when $Q_{r}$ and $\eta_{\mathrm{bc}}$ were correlated and alongestuary winds caused significant variability in $u^{\prime}$. Over longer periods, wind effects in the Hudson tended to average out such that $Q_{r}$ dominated the variation in $\bar{u}$, and $\partial s / \partial x$ dominated the variation in $u^{\prime}$. However, with the extra forcing terms, the model reproduced the meteorological scale variability that was apparent in the observations. The meteorological band variability can be important for simulating conditions during extreme events, when correlations among river discharge, sea level, and local wind are most likely to alter estuarine salinities or velocities.

While modifications improved the predictive ability of the model, an important limitation remains with how the model represents conditions during neap tides with moderate to high river discharge. Discrepancies with observations of salinity and stratification were greatest during weak tidal mixing and moderate to high freshwater input, as the model failed to capture the propagation of the salinity field up the estuary during neap tides. During such conditions, the Hudson is effectively a two-layer system, with a nearly fresh surface layer, 
nearly oceanic salinities in the bottom layer, and a sharp pycnocline. The Hansen and Rattray formulation for $u^{\prime}$ and $s^{\prime}$ restricts the vertical variation of the salinity and velocity, so when the system becomes more like a salt wedge, the model performance decreases.

At least two factors may contribute to the degradation of model performance as the estuary becomes more two layer. As seen in the observations, the alongestuary gradient in bottom or surface salinities can be relatively weak, but the depth-averaged baroclinic pressure gradient is nonzero. Instead of surface and bottom salinities, the depth-integrated $\partial s / \partial x$ depends on the along-estuary slope of the pycnocline. In the model, the polynomial shape functions for $u^{\prime}$ and $s^{\prime}$ are constant, and thus the bottom and surface layer thicknesses are fixed. The layer thicknesses can also change on tidal time scales, as the asymmetry of tidal straining creates a thicker bottom boundary layer during floods and suppresses the boundary layer during ebbs. Correlations between the vertical structure of velocity and salinity at the tidal time scale may enhance up-estuary propagation of the salinity field during these periods, but are not included in the model. Given the inherent limitations of constraining the layer thicknesses, the Hansen and Rattray approach performs well over the observation period. However, significant improvement of the predictive skill may require spatial variability in the structure functions, adding considerable complexity to the model formulation.

The model works relatively well in the Hudson because estuarine circulation dominates the longitudinal salt flux. However, in estuaries where tidal processes contribute significantly to the salt flux, the results may be more sensitive to the formulation for $K_{h}$. We applied a parameterization (MacCready 2007) for tidal pumping at the mouth (Stommel and Farmer 1952) and lateral stirring in the estuary (Banas et al. 2004), but the results did not change appreciably with changes to $K_{h}$. Estuaries that are shallower, wider have greater bathymetric variability or stronger tidal forcing could offer more rigorous testing of the $K_{h}$ parameterization.

The Hudson River observations offered an extensive dataset to test the model, but we have begun to address the validity of this approach for other estuaries. As an alternative case, San Francisco Bay offers an interesting comparison to the Hudson because of differences in bathymetry. The Hudson has a relatively straight, narrow channel of uniform depth for much of its length, while San Francisco Bay has a channel of variable depth passing through a series of broad, shallow bays. As noted previously (MacCready 2004, 2007), comparisons between observations and equilibrium salinity distributions from the one-dimensional, tidally averaged model offers promise that the approach can be extended to estuaries beyond the Hudson. The equilibrium model results in San Francisco Bay suggest that spatial variability in depth and cross-sectional area have a much greater impact on response of the system to changes in discharge than effects of stratification on vertical mixing. However, as demonstrated in the Hudson, temporal responses to changes in forcing are integral to simulating the salinity field, so the model should be tested against time series of salinity and velocity in estuaries over a range of parameter space. We suspect that the model may be less effective in estuaries that are wide (relative to the depth) or short (relative to the tidal excursion), but even model failures can be instructive for understanding the underlying estuarine dynamics.

This simplified modeling approach has potential benefits relative to more complex three-dimensional hydrodynamic models. With minimal inputs of $Q_{r}$ and $U_{t}$ (and more completely, $\eta_{\mathrm{bc}}$ and $\tau_{w}$ ), the model can quickly run for very long periods or over many different scenarios. Historical data can be input as forcing to generate time series of salinity distribution, stratification, and residual velocity to evaluate habitat distribution or sediment transport capacity. Alternatively, the model could simulate effects of changes in freshwater input due to watershed management or climate change. In any case, interpretation of the results is aided by the focus on relatively elementary processes.

Acknowledgments. This research was supported by the Hudson River Foundation Grant 005/03A, NSF Grant OCE-0452054, and by the Postdoctoral Scholar Program at the Woods Hole Oceanographic Institution, with funding provided by the J. Seward Johnson Fund.

\section{REFERENCES}

Abood, K. A., 1974: Circulation in the Hudson River estuary. Hudson River Colloquium, O. A. Roels, Ed., Annals of the New York Academy of Sciences, Vol. 250, New York Academy of Sciences, 38-111.

Banas, N. S., B. M. Hickey, P. MacCready, and J. A. Newton, 2004: Dynamics of Willapa Bay, Washington, a highly unsteady partially mixed estuary. J. Phys. Oceanogr., 34, 2413 2427.

Bowen, M. M., and W. R. Geyer, 2003: Salt transport and the time-dependent salt balance of a partially stratified estuary. $J$. Geophys. Res., 108, 3158, doi:10.1029/2001JC001231.

Chatwin, P. C., 1976: Some remarks on the maintenance of the salinity distribution in estuaries. Estuarine Coastal Mar. Sci., 4, 555-566.

Csanady, G. T., 1973: Wind-induced barotropic motions in long lakes. J. Phys. Oceanogr., 3, 429-438.

Dronkers, J., and J. van de Kreeke, 1986: Experimental determi- 
nation of salt intrusion mechanisms in the Volkerak estuary. Neth. J. Sea Res., 20, 1-19.

Fischer, H. B., 1972: Mass transport mechanisms in partially stratified estuaries. J. Fluid Mech., 53, 671-687.

— E. E. List, R. C. Y. Koh, J. Imberger, and N. H. Brooks, 1979: Mixing in Inland and Coastal Waters. Academic Press, $483 \mathrm{pp}$.

Garvine, R. W., 1985: A simple model of estuarine subtidal fluctuations forced by local and remote wind stress. J. Geophys. Res., 90, 11 945-11 948.

Geyer, W. R., 1997: Influence of wind on dynamics and flushing of shallow estuaries. Estuarine Coastal Mar. Sci., 44, 713-722.

— J. H. Trowbridge, and M. M. Bowen, 2000: The dynamics of a partially mixed estuary. J. Phys. Oceanogr., 30, 2035-2048.

Hansen, D. V., and M. Rattray Jr., 1965: Gravitational circulation in straits and estuaries. J. Mar. Res., 23, 104-122.

Hetland, R. D., and W. R. Geyer, 2004: An idealized study of the structure of long, partially mixed estuaries. J. Phys. Oceanogr., 34, 2677-2691.

Hunkins, K., 1981: Salt dispersion in the Hudson Estuary. J. Phys. Oceanogr., 11, 729-738.

Janzen, C. D., and K.-C. Wong, 2002: Wind-forced dynamics at the estuary-shelf interface of a large coastal plain estuary. $J$. Geophys. Res., 107, 3138, doi:10.1029/2001JC000959.

Kranenberg, C., 1986: A time scale for long-term salt intrusion in well-mixed estuaries. J. Phys. Oceanogr., 16, 1329-1331.

Large, W. G., and S. Pond, 1981: Open ocean momentum flux measurements in moderate to strong winds. J. Phys. Oceanogr., 11, 324-336.

Lerczak, J. A., W. R. Geyer, and R. J. Chant, 2006: Mechanisms driving the time-dependent salt flux in a partially stratified estuary. J. Phys. Oceanogr., 36, 2283-2298.

Li, M., L. Zhong, and W. C. Boicourt, 2005: Simulations of Chesapeake Bay estuary: Sensitivity to turbulence mixing parameterizations and comparison with observations. J. Geophys. Res., 110, C12004, doi:10.1029/2004JC002585.

MacCready, P., 1999: Estuarine adjustment to changes in river flow and tidal mixing. J. Phys. Oceanogr., 29, 708-726.

,- 2004: Toward a unified theory of tidally-averaged estuarine salinity structure. Estuaries, 27, 561-570.

_ 2007: Estuarine adjustment. J. Phys. Oceanogr., 37, $2133-$ 2145.

Monismith, S. G., W. Kimmerer, J. R. Burau, and M. T. Stacey, 2002: Structure and flow-induced variability of the subtidal salinity field in northern San Francisco Bay. J. Phys. Oceanogr., 32, 3003-3019.
Noble, M. A., W. W. Schroeder, W. J. Wiseman Jr., H. F. Ryan, and G. Gelfenbaum, 1996: Subtidal circulation patterns in a shallow, highly stratified estuary: Mobile Bay, Alabama. $J$. Geophys. Res., 101, 25 689-25 703.

Okubo, A., 1973: Effect of shoreline irregularities on streamwise dispersion. Neth. J. Sea Res., 6, 213-224.

Stacey, M. T., and D. K. Ralston, 2005: The scaling and structure of the estuarine bottom boundary layer. J. Phys. Oceanogr., 35, 55-71.

Stedfast, D. A., 1980: Cross sections of the Hudson River estuary from Troy to New York City, New York. U.S. Geological Survey Water-Resources Investigations 80-24, 70 pp.

Stommel, H., and H. G. Farmer, 1952: On the nature of estuarine circulation. Part I (chapters 3 and 4), Woods Hole Oceanographic Institution Tech. Rep. 52-88, 172 pp.

Taylor, G. I., 1953: Dispersion of soluble matter in solvent flowing slowly through a tube. Proc. Roy. Soc. London, A219, 186203.

van de Kreeke, J., and K. Robaczewska, 1989: Effect of the wind on the vertical circulation and stratification in the Volkerak Estuary. Neth. J. Sea Res., 23, 239-253.

Wang, D.-P., 1979: Wind-driven circulation in the Chesapeake Bay, winter 1975. J. Phys. Oceanogr., 9, 564-572.

, and A. J. Elliott, 1978: Non-tidal variability in the Chesapeake Bay and Potomac River: Evidence for non-local forcing. J. Phys. Oceanogr., 8, 225-232.

Warner, J. C., W. R. Geyer, and J. A. Lerczak, 2005: Numerical modeling of an estuary: A comprehensive skill assessment. $J$. Geophys. Res., 110, C05001, doi:10.1029/2004JC002691.

Weisberg, R. H., 1976: The nontidal flow in Providence River of Naragansett Bay: A stochastic approach to estuarine circulation. J. Phys. Oceanogr., 6, 721-734.

Wells, A. W., and J. R. Young, 1992: Long-term variability and predictability of Hudson River physical and chemical characteristics. Estuarine Research in the 1980's, C. L. Smith, Ed., State University of New York Press, 29-58.

Wilmott, C. J., 1981: On the validation of models. Phys. Geogr., 2, 184-194.

Wong, K. C., and J. E. Moses-Hall, 1998: The tidal and subtidal variations in the transverse salinity and current distributions across a coastal plain estuary. J. Mar. Res., 56, 489-517.

_ , and A. Valle-Levinson, 2002: On the relative importance of the remote and local wind effects on the subtidal exchange at the entrance to the Chesapeake Bay. J. Mar. Res., 60, 477498. 